\title{
College Mental Health: A Vulnerable Population in an Environment with Systemic Deficiencies
}

\author{
Richard Balon $^{1}$ • Eugene V. Beresin ${ }^{2}$ • John H. Coverdale ${ }^{3}$ - Alan K. Louie ${ }^{4}$. \\ Laura Weiss Roberts ${ }^{4}$
}

Received: 12 June 2015 / Accepted: 17 June 2015 /Published online: 1 September 2015

(C) Academic Psychiatry 2015

From time to time, attention is brought to the status of mental health - or, rather, mental illness - on US college campuses. We thank Michelle Riba, Daniel Kirsch, Adele Martel, and Michelle Goldsmith for guest editing a special collection of articles on this topic for this issue of the journal.

A May 2015 article in the New York Times [1] reported that nearly one in six college students was diagnosed with or treated for anxiety within the previous 12 months. The article also pointed out that anxiety has surpassed depression as the most common psychiatric diagnosis among college students, although rates of depression are also on the rise.

It is well established that college students, often desperately in need of psychological and psychiatric services, find that these services are not always available on their campuses. Further, only a handful of students with psychiatric needs bring their concerns to the attention of professionals within their college-based systems of care. And we continue to be stunned by the numbers of suicides and sexual assaults at our own or nearby colleges.

When these findings and tragic events are reported, everybody - students, parents, media, health professionals, and politicians - passionately talks about the inadequacy of current systems of care across US undergraduate programs. The help provided to US college students is widely insufficient. Stakeholders also often comment on the perpetual problem of educating students, families, and college personnel about the as-

Richard Balon

rbalon@wayne.edu

1 Wayne State University, Detroit, MI, USA

2 Harvard Medical School, Boston, MA, USA

3 Baylor College of Medicine, Houston, TX, USA

4 Stanford University, Stanford, CA, USA sessment of and treatment for mental health problems that are pervasive on college campuses.

But these concerns do not lead to change. Typically, within a few weeks after a highly visible media report, the attention winds down. The college where an incident occurred continues to investigate. Then, the school perhaps institutes regulations or measures intended to prevent the reported serious mental health issue for other students in the future. Sometimes, the school provides an increase in support for mental health services but maybe only temporarily. Sadly, most of these measures are "patchwork" remedies that do not address the underlying substantial and systemic problems. Rarely does a comprehensive plan to address psychiatric, emotional, and behavioral problems on campus emerge.

College mental health issues are much larger than recognized and seldom adequately addressed. As Riba et al. [2] point out, more than 20 million individuals are enrolled in US institutions of higher education. These are mostly people of a vulnerable age, in their late adolescence or early adulthood, which is frequently a time for a first episode of serious mental disorders. In 2008, Blanco and colleagues [3] estimated that almost half of college-aged individuals had a psychiatric disorder during the previous year and that the overall rate of psychiatric disorders was not different between collegeattending individuals and noncollege-attending individuals. There were some differences - college students had a greater risk of alcohol use disorders than their noncollege peers, yet lower risk for drug use disorders, nicotine dependence, and bipolar disorder. Fewer than $25 \%$ of individuals with a mental disorder sought treatment in the year before Blanco et al.'s [3] survey, and college students were less likely to receive treatment for alcohol or drug use disorders than their noncollege peers. A structured-interview study performed by Ohayon and Roberts [4] involving more than 19,000 young adults and nearly 2200 students living on a university campus found that 
$23 \%$ of college students reported a depressed mood and $3 \%$ met criteria for major depressive disorder in the previous month.

What mental services are available for this huge number of young persons suffering from various problems and disorders? As many have pointed out, college students' need for mental health care has increased dramatically, leaving campus counseling and mental health centers struggling to meet the demands [5]. The 2014 National Survey of College Counseling Centers [6] provides some interesting, yet discouraging, data. According to this report, $11 \%$ (approximately 360,000 ) of 3.3 million students eligible for counseling services sought individual or group counseling during the previous year. Because this survey presents results from only 275 colleges and 3.3 million students, the total number seeking counseling for all US colleges is clearly much higher (approximately 2.5 million).

This survey also found that the average ratio of paid mental health professionals to students is 2081, ranging from 1216 on smaller campuses (those with less than 7500 students) to 4208 on large campuses (this with more than 15,000 students). The average number of full-time equivalent mental health professionals providing services on campuses was 6.2 . Only $7 \%$ of 2 -year college students have access to an on-campus psychiatrist, whereas $54 \%$ of 4-year college students have such access. Yet $86 \%$ of directors of counseling services reported a steady increase of students arriving on campuses who were already on psychiatric medications, and $94 \%$ of centers reported an increase in arrivals of students with serious psychological problems. Also, the average number of college mental health center clients taking psychotropic medication was $26 \%$.

The survey noted increases over the previous 5 years in the use of psychiatric medications $(60 \%)$ and in the reporting of clinical depression (58\%) and anxiety disorders (89\%). Directors of the 275 centers responding to this survey reported 125 student suicides in the previous year; among these students, $61 \%$ were depressed, $21 \%$ had relationship problems, and $11 \%$ had academic problems.

The number of new mental health professional positions has been minuscule, however. In addition, many places limit the number of sessions provided, few provide ongoing psychotherapy over and above psychiatric evaluation and a primary treatment of medication management, and only $20 \%$ of centers have increased their psychiatric consulting hours.

These data suggest that college mental health services in general and psychiatric services in particular are inadequate and not enough is being done to rectify this problem. The psychiatric care of college students is often further handicapped by vacation and leaves, which interrupt students' care by college mental health providers, and loss of social and family support systems while students are at college.
Given the magnitude of the problem, colleges provide very little education for students, their parents, faculty, resident advisors, and administrators about mental illness and alcohol and drug use disorders, including their risk, prevention, symptoms, benefits of treatment, and local resources for obtaining help. To compound these problems, few students seek mental health services [3], partially because of the stigma associated with mental illness and fear of having a "record."

The situation is even more complicated by the mentioned paucity of psychiatric services on college campuses, and few colleges inform students and parents about local resources on campus and in the community. In many large universities with medical schools, there is minimal to no connection between the college mental health centers and departments of psychiatry-a situation that might seem paradoxical. Colleges and universities have expressed concerns, however, that students in need of mental health services might be reluctant to approach medical school faculty, especially if the students themselves were considering applying for medical school.

Despite good intentions to do the best for students' differences in financing, the administration and accreditation of college mental health systems and medical schools stand as potential barriers to a continuum of care. Additionally, college health insurance plans are often not accepted by the medical schools on the same university campuses, or the benefits are limited, and almost no benefits are available after the college mental health benefits are exhausted. Coverage has improved with the arrival of the Patient Protection and Affordable Care Act [7], because young people can be covered by their parents' insurance until age 26. As noted above, however, there is little guidance for families as to the local services that will accept their insurance. Finally, college mental health issues involve not only entities defined in the Diagnostic and Statistical Manual of Mental Disorders [8] but also many other emotional and behavioral problems, such as nonprescription stimulant use [9], risky sexual behavior, self-harm behaviors, sexual assaults, binge drinking, reckless driving, unhealthy eating/dietary and sleep patterns, and especially relationship difficulties. Such intense problems for college students may not merit a psychiatric diagnosis, which may further complicate and perhaps preclude the delivery of professional help despite the request or need for it.

We are facing a true and profound crisis of college mental health. We cannot afford to jeopardize our future, our nation's youth. What can be done to correct this situation? Some of the many possible solutions are presented in the collection of articles on college mental health in this issue of Academic Psychiatry. Others [5] have suggested population-based approaches, such as student-to-student programs that capitalize on students' natural inclination to assist their peers. 
Seritan et al. [10] reported an encouraging experience with the Office of Student Wellness at the University of California Davis. The mission of this office is "to design and deliver an educational campaign regarding medical student wellness; develop and implement measures that improve students' physical and emotional health; and serve as a triage point for students with mental health difficulties" [10], p. 80]. The program "combines prevention with education and involves students, families, residents, faculty, and staff to unite them in the common goal of improving student wellness" [10, p. 84]. Programs like this could serve as a blueprint for other college campuses too. But these would be only the first steps.

Students, their parents, college staff and administrators, politicians, and the public will benefit from greater knowledge of the immediate need for a well-funded, comprehensive, and functional college mental health model system. This priority should be based in part on an understanding of the prevalence of mental disorders, sexual assaults, bullying, and other serious issues that threaten student well-being and on an understanding of emotional, interpersonal, and family problems that students commonly experience on college campuses.

Individual colleges should also identify factors that promote positive effects on their students' mental health and that aid resilience, as well as those that contribute to negative effects, and identify and modify barriers to the utilization of mental health services. We also need to develop, evaluate, and apply best-evidence and multipronged approaches that reduce emotional distress, prevent alcohol- and substance-related problems, and promote safety on college campuses. College courses that examine in a scholarly manner health behaviors (e.g., sleep, eating, sex) and behavior change should be strongly encouraged and given credits in the curriculum. They should not just be relegated to extracurricular offerings or appended to an athletic program.

We also need to create collaborative relationships between college mental health centers and departments of psychiatry and psychology at college campuses or nearby universities and with high-quality community mental health services that accept student and family insurance policies. Aligning psychology and psychiatric departments with college mental health services will add to the intellectual and fiscal resources in the service of addressing the mental health needs of college students. These services are best integrated with college medical services, because stigmatizing beliefs will be challenged when students learn that one is integral to the other. Finally, psychiatry residents need training to take care of college students in a far more extensive manner than is currently provided in psychiatry training programs.

Disclosures On behalf of all authors, the corresponding author states that there is no conflict of interest.

\section{References}

1. Hoffman J. Anxious students strain college mental health centers. New York Times. 27 May 2015. Available at http://well.blogs. nytimes.com/2015/05/27/anxious-students-strain-college-mentalhealth-centers/. Accessed 12 June 2015.

2. Riba M, Kirsch D, Martel A, Goldsmith M. Preparing and training mental health workforce. Acad Psychiatry. 2015. doi:10.1007/ s40596-015-0406-x.

3. Blanco C, Okuda M, Wright C, Hasin DS, Grant BF, Liu SM, et al. Mental health of college students and their non-college-attending peers: results from the National Epidemiologic Study on Alcohol and Related Conditions. Arch Gen Psychiatry. 2008;65(12): 1429-37.

4. Ohayon MM, Roberts LW. Links between occupational activities and depressive mood in young adult populations. J Psychiatr Res. 2014;49:10-7.

5. Kirsch DJ, Pinder-Amaker SL, Morse C, Ellison ML, Doerfler LA, Riba MB. Population-based initiatives in college mental health: students helping students to overcome obstacles. Curr Psychiatry Rep. 2014;16(12):525.

6. Gallagher RP, Taylor R. National survey of college counseling centers 2014. Available at http://www.collegecounseling.org/wpcontent/uploads/NCCCS2014_v2.pdf. Accessed 3 May 2015.

7. Office of the Legislative Counsel. Patient Protection and Affordable Care Act. May 2010. Available at http:/www.hhs.gov/healthcare/ rights/law/. Accessed 12 June 2015.

8. American Psychiatric Association. Diagnostic and statistical manual of mental disorders. 5th ed. Arlington: American Psychiatric Press; 2014.

9. Reid AM, Graziano PA, Balkhi AM, McNamara JP, Cottler LB, Meneses E, et al. Frequent nonprescription stimulant use and risky behaviors in college students: the role of effortful control. J Am Coll Health. 2015;63(1):23-30.

10. Seritan AL, Rai G, Servis M, Pomeroy C. The office of student wellness: innovating to improve student mental health. Acad Psychiatry. 2015;39(1):80-4. 